\title{
Facile single-step synthesis of porous carbons as efficient $\mathrm{CO}_{2}$ adsorbents
}

\section{(Supporting information)}

Shenfang Liu ${ }^{\text {a }}$, Qian Li ${ }^{\text {a }}$, Linlin Wang ${ }^{\text {b }}$, Rui Ma *a a, Jing Zou ${ }^{\text {a }}$ Lijiao Huang ${ }^{\text {a }}$, Xin $\mathrm{Hu}^{*}$, a

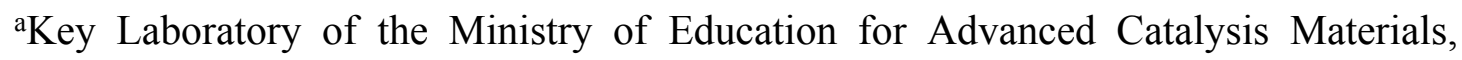
Zhejiang Normal University, Jinhua 321004, PR China

${ }^{\mathrm{b} C o l l e g e}$ of Engineering, Zhejiang Normal University, 688 Yingbin Ave. Jinhua 321004, PR China

${ }^{*}$ Corresponding author's e-mail: mr@zjnu.cn (R.M.); huxin@zjnu.cn (X.H.); phone: 86-579-8228-2269; fax: 86-579-8228-8269.

\section{Characterization}

Powdered X-ray diffraction (XRD) patterns were carried out on a PHILIPS PW3040/60 powder diffractometer using $\mathrm{CuK} \alpha$ radiation $(\lambda=0.15406 \mathrm{~nm})$. Scanning electron microscopy (SEM Hitachi S-4800) was used to observe the morphology of the samples of carbon materials. Further details of the pore structure were determined by transmission electron microscopy (TEM, JEOL-2100F) operated at $200 \mathrm{kV}$. Nitrogen adsorption and desorption isotherms were measured on a Beishide 3H-2000PS2 sorption analyzer at $-196^{\circ} \mathrm{C}$. Ultrahigh-purity $\mathrm{N}_{2}$ (99.999\%, Shanghai Pujiang Gas Co., Ltd) was used for measurement. Before measurement, the samples were degassed in a vacuum at $200^{\circ} \mathrm{C}$ for at least $12 \mathrm{~h}$. The specific surface area $\left(S_{B E T}\right)$ was calculated according to the multipoint Brunauer-Emmett-Teller (BET) method from the 
adsorption data in the relative pressure range between 0.01 and 0.1 . The total micropore volume $\left(V_{t}\right)$ was deduced from the $\mathrm{N}_{2}$ adsorption data by the t-plot method, and the total pore volume $\left(V_{0}\right)$ was estimated from the adsorbed amount of liquid nitrogen at a relative pressure of 0.99 . The pore size distribution was calculated using the density functional theory (DFT) method.

The $\mathrm{CO}_{2}$ adsorption isotherms were measured using the Beishide $3 \mathrm{H}-2000 \mathrm{PS} 2$ sorption analyzer at $0^{\circ} \mathrm{C}$ and $25^{\circ} \mathrm{C}$, respectively. Pure $\mathrm{CO}_{2}(99.99 \%$, Shanghai Pujiang Gas Co., Ltd) was used for adsorption. Prior to each adsorption experiment, the sample was degassed for $12 \mathrm{~h}$ at $200^{\circ} \mathrm{C}$ to remove the guest molecules from the pores. The volume of narrow micropores (with sizes $<1 \mathrm{~nm}$ ), $V_{n}$, was calculated from $\mathrm{CO}_{2}$ adsorption at $0^{\circ} \mathrm{C}$ using the Dubinin-Radushkevich (D-R) equation. The measurements were repeated for each sample, until the values fell within $\pm 2 \%$ of each other.

\section{Measurement of dynamic $\mathrm{CO}_{2}$ uptake of the sorbents}

The dynamic $\mathrm{CO}_{2}$ uptake of the sorbents was tested on a fixed-bed reactor schematically illustrated in Scheme S1 at 1 bar and $25^{\circ} \mathrm{C}$. First, the sample was heated at $100^{\circ} \mathrm{C}$ for $1 \mathrm{~h}$ under $\mathrm{N}_{2}$ at a flow rate of $20 \mathrm{~mL} / \mathrm{min}$. The gas flow was shifted from nitrogen to a $10 \%$ mixture of $\mathrm{CO}_{2}$ in $\mathrm{N}_{2}$ at a flow rate of $10 \mathrm{~mL} / \mathrm{min}$, when the sample temperature was lowered to $25^{\circ} \mathrm{C}$. The effluent gases were monitored online using an Agilent 7820A gas chromatograph with a thermal conductivity detector (TCD). From the breakthrough curves, the dynamic $\mathrm{CO}_{2}$ capture capacity on an adsorbent was calculated. 


\section{Measurement of $\mathrm{CO}_{2}$ adsorption kinetics}

The adsorption kinetics of $\mathrm{CO}_{2}$ was measured in a thermogravimetric analyzer (NETZSCH STA 449C). In the kinetic analysis, the sample ( $\sim 5 \mathrm{mg})$ was degassed under a $\mathrm{He}$ stream at $200^{\circ} \mathrm{C}$ for $1 \mathrm{~h}$. Next, the temperature was cooled to the experimental temperature of $25^{\circ} \mathrm{C}$. Then the $\mathrm{CO}_{2}$ gas was fed into the test chamber with a flow rate of $50 \mathrm{~mL} / \mathrm{min}$ and the weight variation with time was recorded.

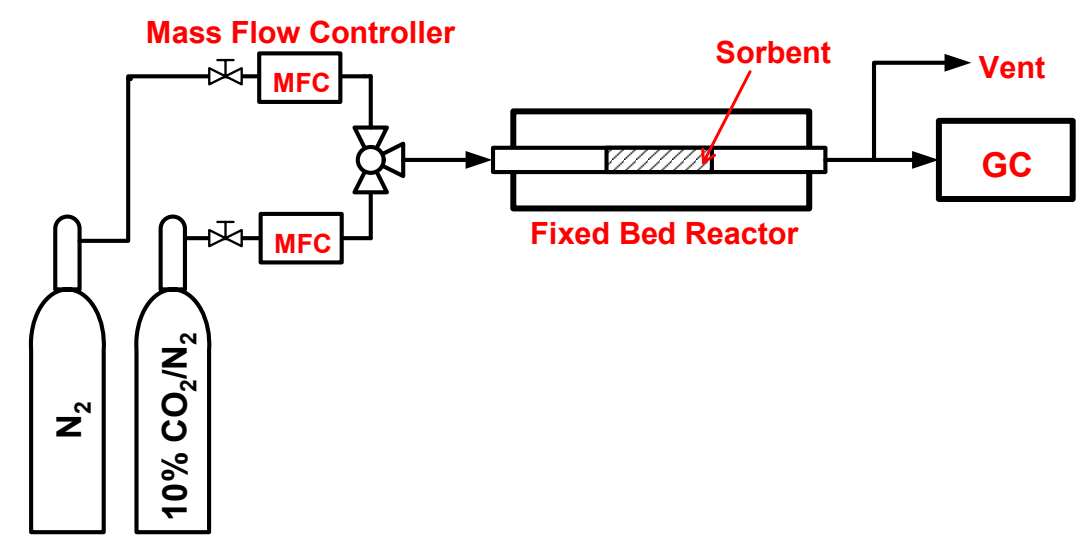

Scheme S1. Schematic of the fixed-bed reactor system.

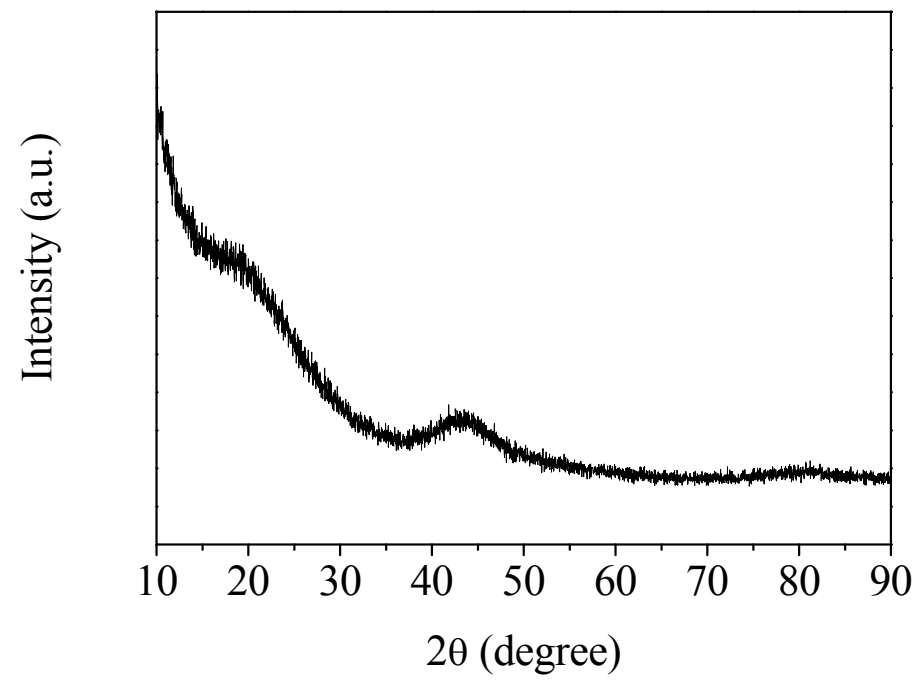

Figure S1. XRD pattern of RC-650-1.5. 


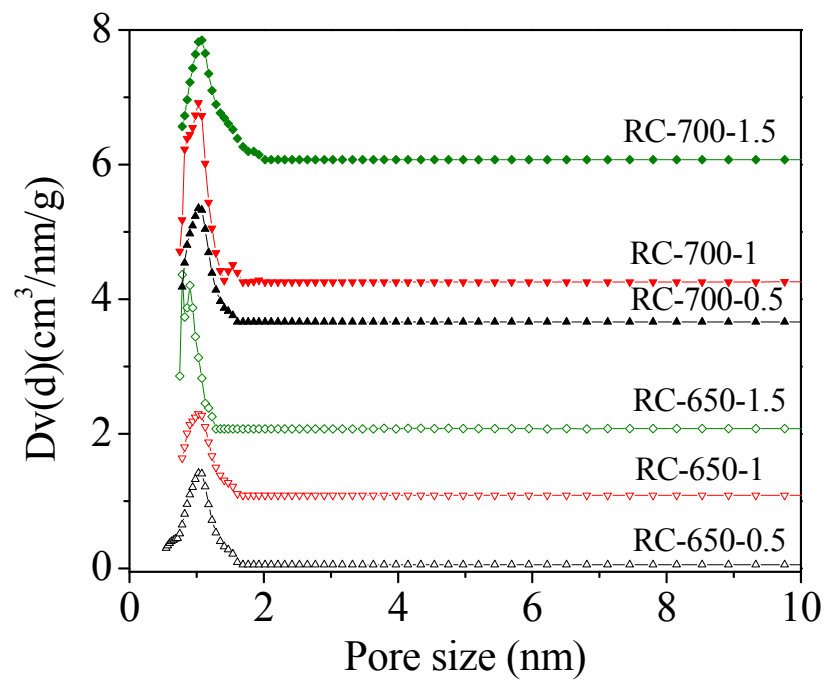

Figure S2. Pore size distribution of the samples prepared at $650^{\circ} \mathrm{C}$ and $700^{\circ} \mathrm{C}$.

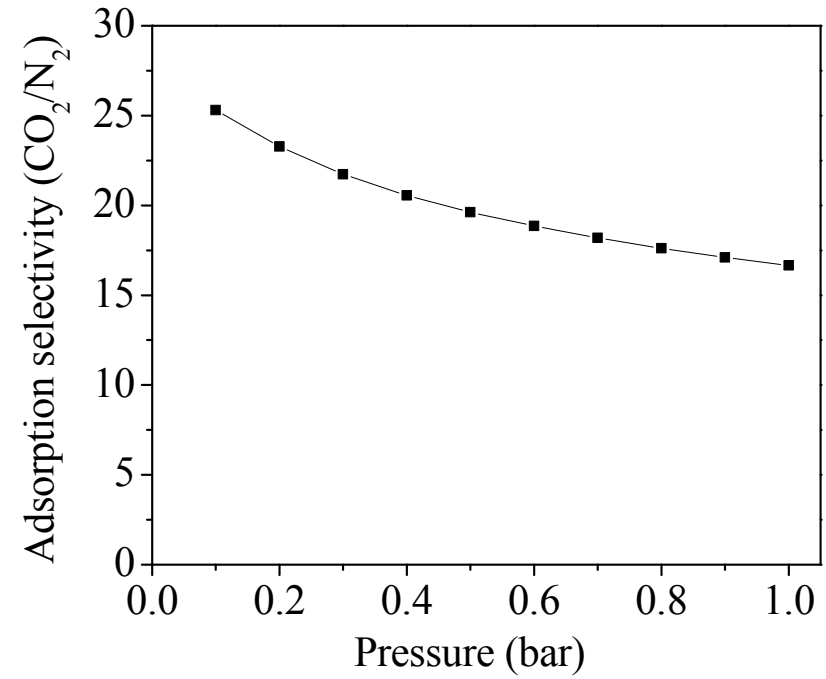

Figure S3. The IAST-predicted adsorption selectivity of RC-650-1.5 for a binary mixture of $10: 90 \mathrm{CO}_{2} / \mathrm{N}_{2}$ at $25^{\circ} \mathrm{C}$ and up to 1 bar. 
Table S1. Comparison of the $\mathrm{CO}_{2}$ adsorption $\left(25^{\circ} \mathrm{C}\right.$ and 1 bar) for different sorbents

\begin{tabular}{ccc}
\hline Sample & $\begin{array}{c}\mathrm{CO}_{2} \text { uptake } \\
(\mathrm{mmol} / \mathrm{g})\end{array}$ & Ref. \\
\hline AA750 & 2.7 & $\mathrm{~S} 1$ \\
OM-CNS & 3.0 & $\mathrm{~S} 2$ \\
AC-4-700 & 3.5 & $\mathrm{~S} 3$ \\
PC-700 & 3.6 & $\mathrm{~S} 4$ \\
CEMFAET & 3.8 & $\mathrm{~S} 5$ \\
CP-2-600 & 3.9 & $\mathrm{~S} 6$ \\
CPTHB-6 & 4.0 & $\mathrm{~S} 7$ \\
MOF-2 & 0.6 & $\mathrm{~S} 8$ \\
MOF-505 & 3.3 & $\mathrm{~S} 8$ \\
ZIF-78 & 2.7 & $\mathrm{~S} 9$ \\
COF-102 & 3.5 & S10 \\
RC-650-1.5 & 4.1 & This study \\
\hline
\end{tabular}

\section{References}

S1. Balahmar, N.; Mitchell, A. C.; Mokaya, R., Generalized Mechanochemical Synthesis of Biomass-Derived Sustainable Carbons for High Performance $\mathrm{CO}_{2}$ Storage. Adv. Energy Mater. 2015, 5, (22), 1500867.

S2. Zheng, L.; Li, W. B.; Chen, J. L., Nitrogen doped hierarchical activated carbons derived from polyacrylonitrile fibers for $\mathrm{CO} 2$ adsorption and supercapacitor electrodes. RSC Adv. 2018, 8, (52), 29767-29774.

S3. Sevilla, M.; Fuertes, A. B., Sustainable porous carbons with a superior performance for $\mathrm{CO}_{2}$ capture. Energy Environ. Sci. 2011, 4, (5), 1765-1771.

S4. Chen, C.; Yu, Y.; He, C.; Wang, L.; Huang, H.; Albilali, R.; Cheng, J.; Hao, Z., Efficient capture of $\mathrm{CO} 2$ over ordered micro-mesoporous hybrid carbon nanosphere. Appl. Surf. Sci. 2018, 439, 113-121. 
S5. Plaza, M. G.; Pevida, C.; Martin, C. F.; Fermoso, J.; Pis, J. J.; Rubiera, F., Developing almond shell-derived activated carbons as $\mathrm{CO}_{2}$ adsorbents. Sep. Purif. Technol. 2010, 71, (1), 102-106.

S6. Xia, Y.; Mokaya, R.; Walker, G. S.; Zhu, Y., Superior $\mathrm{CO}_{2}$ Adsorption Capacity on N-doped, High-Surface-Area, Microporous Carbons Templated from Zeolite. $A d v$. Energy Mater. 2011, 1, (4), 678-683.

S7. Sevilla, M.; Valle-Vigón, P.; Fuertes, A. B., N-Doped Polypyrrole-Based Porous Carbons for $\mathrm{CO}_{2}$ Capture. Adv. Funct. Mater. 2011, 21, (14), 2781-2787.

S8. Millward, A. R.; Yaghi, O. M., Metal-Organic Frameworks with Exceptionally High Capacity for Storage of Carbon Dioxide at Room Temperature. J. Am. Chem. Soc. 2005, 127, (51), 17998-17999.

S9. Furukawa, H.; Yaghi, O. M., Storage of Hydrogen, Methane, and Carbon Dioxide in Highly Porous Covalent Organic Frameworks for Clean Energy Applications. J. Am. Chem. Soc. 2009, 131, (25), 8875-8883.

S10. Tian, Z.; Huang, J.; Zhang, X.; Shao, G.; He, Q.; Cao, S.; Yuan, S., Ultramicroporous $\mathrm{N}$-doped carbon from polycondensed framework precursor for $\mathrm{CO}_{2}$ adsorption. Microporous Mesoporous Mater. 2018, 257, 19-26. 